\title{
Audit Layanan Sistem Informasi Bantuan Operasional Sekolah Kabupaten Bintan Menggunakan Cobit 5.0
}

\author{
Sella Matussaqdiah ${ }^{1}$, Liza Safitri ${ }^{2}$, Hendi Setiawan ${ }^{3}$ \\ ${ }^{1}$ Jurusan Sistem Informasi STT Indonesia Tanjungpinang \\ Jln. Poma Air No. 28 Tanjungpinang Kepulauan Riau Indonesia \\ ${ }^{1}$ sellamtussaqdiah96l@gmail.com \\ ${ }^{2}$ savetree3300@gmail.com, ${ }^{3}$ hendi@sttindonesia.ac.id
}

\begin{abstract}
Intisari- SIBOS merupakan Sistem Informasi Bantuan Operasional Sekolah yang di pantau langsung oleh Dinas Pendidikan Kabupaten Bintan. Permasalahan dari pemakaian Aplikasi SIBOS belum dilakukan audit sehingga belum diketahui efisiensi dan tingkat kapabilitas sistem informasi yang sudah ada. Dalam penelitian ini menggunakan model kapabilitas sebagai alat ukur terhadap jawaban responden dari kuesioner yang dibuat berdasarkan framework cobit 5.0 domain DSS (Deliveri, service and Support) serta sebagai pemberi definisi dan pemahaman proses sistem teknologi informasi yang sedang berjalan. Berdasarkan rekapitulasi jawaban dari para responden, maka didapatkan nilai tingkat kapabilitas. Audit mengambil sample 40 responden, dan telah di sebarkan kuesioner dan diolah menggunakan COBIT 5.0 dengan hasil, SIBOS sudah memiliki tingkat efektifitas yang cukup tinggi berada pada nilai 3,83 atau level 4 (predictable process). Skala penilaian berdasarkan penelitian ini adalah largely achieved yaitu pada angka 71,43 $\%$. Level 4 artinya sistem informasi sudah sesuai dengan yang di harapkan,dalam kondisi bagus dan relevan, sebagian besar dicapai, tidak ada kelemahan signifikan terkait dengan atribut ini yang mungkin ada dalam proses penilaian.

Kata kunci- Audit, Sistem Informasi, COBIT 5.0, Kapabilitas, Predictable Process, Largely Achieved
\end{abstract}

Abstract - SIBOS is an Information System for School Operational Assistance which is directly monitored by the Bintan Regency Education Office. The problem with the use of the SIBOS application has not been audited so that the efficiency and capability level of the existing information system is not known. In this study, the capability model is used as a measuring tool for respondents' answers to the questionnaire based on the DSS 5.0 domain DSS (delivery, service and support) framework as well as providing definitions and understanding of the ongoing information technology system processes. Based on the recapitulation of answers from the respondents, the value of the capability level is obtained. The audit took a sample of 40 respondents, and questionnaires were distributed and processed using COBIT 5.0 with the results, SIBOS already has a high level of effectiveness at a value of 3.83 or level 4 (predictable process). The assessment scale based on this research is largely achieved, namely at $71.43 \%$. Level 4 means that the information system is as expected, in good and relevant conditions, mostly achieved, there are no significant weaknesses related to this attribute that may exist in the assessment process.

Keywords - Audit, Information Systems, COBIT 5.0, Capability, Predictable Process, Largely Achieved

\section{Pendahuluan.}

\section{A. Latar Belakang}

Dinas Pendidikan Kabupaten Bintan sebagai salah satu Instansi Pemerintah yang ada di Kabupaten Bintan yang memiiki banyak tugas dan tanggung jawab, salah satunya penyaluran dan pengontrolan Bantuan Operasional Sekolah (BOS) yang serahkan ke setiap sekolah untuk digunakan semanamestinya untuk menunjang pendidikan di setiap sekolah. Dana yang di berikan pemerintah ke setiap sekolah nantinya akan di laporkan ke dinas pendidikan sebagai laporan penyelenggaraan, pengelolaan dana BOS.

Pelaporan dana BOS di lakukan secara manual, sehingga memungkinkan terjadikan kesalahan data, dan memerlukan waktu yang banyak serta ketelitian dalam pembuatan laporan dana BOS. Maka dalam meningkatkan etos kerja dan dalam rangka percepatan pelaporan dana BOS dengan tanpa mengabaikan prinsip kehati-hatian yang diimbangi dengan semakin berkembang pesatnya kemajuan teknologi, Dinas
Pendidikan Kabupaten Bintan menciptakan yaitu Sistem Informasi Bantuan Operasional Sekolah (SIBOS).

SIBOS merupakan sistem informasi milik Pemerintah Kabupaten Bintan yang digunakan oleh Sekolah-Sekolah Negeri milik pemerintah yang berfungsi untuk mengelolah,dan menvalidasi laporkan Bantuan Operasional Sekolah kepada pemerintah yang di kelolah oleh sekolah-sekolah yang ada di kabupaten Bintan.

SIBOS yang selama ini digunakan belum pernah dilakukan audit secara menyeluruh, oleh karena itu perlu adanya audit atau peninjauan yang dilakukan agar dapat dilakukan evaluasi terhadap kekurangan-kekurangan pada SIBOS, serta mempertahankan atau meningkatkan mutu dan kualitas SIBOS. Audit yang dilakukan menggunakan standar COBIT versi terbaru yaitu COBIT versi 5.0. Di dalam COBIT versi 5.0 terdapat 37 referensi proses di dalam tata kelola teknologi informasi. 37 proses referensi tersebut terbagi dalam 4 domain antara lain Align, Plan, and Organize (APO), Build, Acquare and Implement (BAI), Deliver, Service and Support (DSS), dan Monitor Evaluate Assess (MEA) [1]. Di dalam penelitian ini 
penulis mengambil domain Deliver, Service and Support (DSS).

\section{B. Identifikasi Masalah}

Setelah melakukan pengamatan, wawancara, dan observasi maka penulis menemukan atau menentukan masalah sebagai berikut:

1) Sistem Informasi Bantuan Opersional Sekolah (SIBOS) merupakan salah satu system digunakan di sekolahsekolah yang berada di Kabupaten Bintan, akan tetapi belum adanya proses melakukan audit terhadap SIBOS tersebut.

2) Perlu adanya proses melakukan audit terhadap Sistem Informasi Bantuan Opersional Sekolah (SIBOS) agar sistem dapat berjalan dan berkembang sesuai dengan kebutuhan Sekolah.

\section{Batasan Masalah}

Agar penulisan ini lebih terarah dan tidak meluas serta sesuai dengan tujuan, maka penulis membatasi ruang lingkup penelitian yaitu sebagai berikut:

1) Audit hanya dilakukan pada Sistem Informasi Bantuan Operasional Sekolah Kabupaten Bintan.

2) Audit menggunakan Framework COBIT versi 5.0

3) Domain cobit yaitu Delivery, Service, and Support (DSS) untuk mencari tingkat pelayanan Sistem Informasi Bantuan Operasional Sekolah Kabupaten Bintan.

\section{Metodologi Penelitian}

\section{A. Studi Puastaka}

Mengumpulkan data dan informasi yang berhubungan dengan masalah yang dibahas, dengan cara membaca dan memahami literature-literature dari beberapa buku.

\section{B. Studi Lapangan}

Suatu cara yang dilakukan untuk mendapatkan data-data dan informasi, serta keterangan yang relevan dan akurat mengenai masalah yang diteliti antara lain sebagai berikut:

1) Wawancara

Teknik pengumpulan data dengan cara memberikan beberapa pertanyaan langsung.

2) Observasi

Teknik pengumpulan data dengan melakukan pengamatan secara langsung atau turun kelokasi penelitian untuk mendapatkan data dan informasi yang lebih banyak dan akurat.

3) Dokumentasi

Pengambilan data melalui dokumen tertulis maupun elektronik di sekolah-sekolah di Kabupaten Bintan. Digunakan Sebagai mendukung kelengkapan data yang lain.

4) Kuesioner

Teknik survei kuisioner sebagai metode pengumpulan, pada penelitian ini peneliti menyebarkan kuesioner.

\section{Metode COBIT 5.0}

Pada penelitian ini penggunaan metode COBIT 5.0 lebih fokus ke domain manajemen dibagian struktur Deliver, Service and Support (DSS) [2], domain ini berfokus pada aspek pengiriman teknologi informasi (TI). Ini mencakup bidang bidang seperti pelaksanaan aplikasi dalam sistem TI dan hasilnya, serta proses dukungan yang memungkinkan pelaksanaan sistem TI ini efektif dan efesien.

\section{Alur Penelitian}

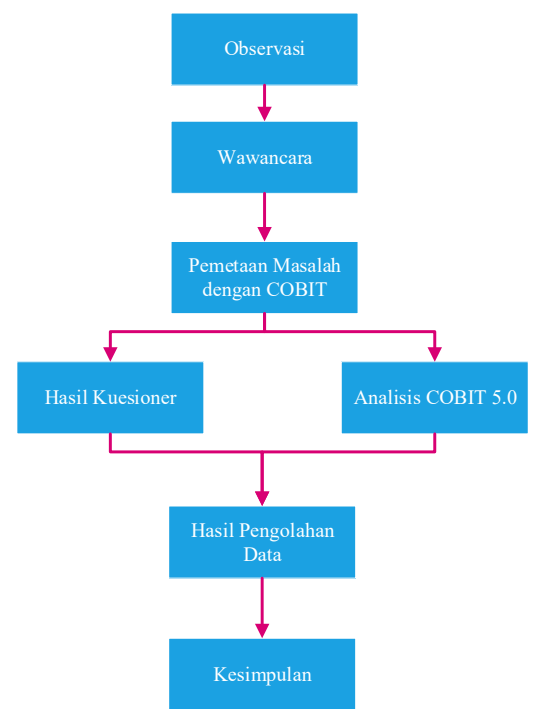

Gambar 1. Alur Penelitian

Berikut ini merupakan tahapan-tahapan alur penelitian yang merujuk ari gambar 1 diatas:

1) Tahap awal dimulai dengan mengumpulkan referensi mengenai penelitian dan melakukan observasi.

2) Setelah melakukan referensi dan observsi, tahap selanjutnya ialah memahami referensi, membuat daftar pertanyaan untuk wawancara dan juga daftar kuesioner untuk disebakan kepada pengguna aplikasi SIBOS.

3) Tahap selanjutnya adalah menentukan sample dari pengguna aplikasi SIBOS yang memenuhi kriteria dari pemillihan sampel.

4) Setelah sample ditentukan, selanjutnya data akan dikumpulkan dengan melakukan wawancara kepada tata usaha dari sekolah yang menggunakan aplikasi SIBOS serta menyebarkan kuisioner kepada pengguna aplikasi SIBOS yang merupakan sample dari penelitian ini.

5) Setelah pengumpulan data dilakukan, maka data akan diolah dan dianalisis sesuai dengan metode COBIT 5.0 untuk perhitungan tingkat kapabilitas dan skala penilaian.

6) Tahap akhir dari penelitian ini ialah tingkat kapabilitas (capability level) dari masing-masing sub domain DSS (Deliver, Service, and Support) serta yang akan dibuat berdasarkan hasil pengolahan serta analisis data. 


\section{LANDASAN TEORI}

\section{A. Pengertian Audit}

Audit merupakan suatu pemeriksaan yang dilakukan secara kritis dan sistematis oleh pihak yang independen, terhadap laporan keuangan yang telah disusun oleh manajemen beserta catatan-catatan pembukuan dan bukti-bukti pendukungnya, dengan tujuan untuk dapat memberikan pendapat mengenai kewajaran laporan keuangan tersebut [3]. Audit atau pemeriksaan dalam arti luas bermakna evaluasi terhadap suatu organisasi, sistem, proses, atau produk.

\section{B. Audit Sistem Informasi}

Audit sistem informasi adalah proses pengumpulan dan evaluasi bukti-bukti untuk menentukan apakah sistem komputer yang digunakan telah dapat melindungi aset milik organisasi, mampu menjaga integritas data, dapat membantu pencapaian tujuan organisasi secara efektif, serta menggunakan sumber daya yang dimiliki secara efisien [4]. Ada beberapa aspek yang diperiksa pada audit sistem informasi yakni audit secara keseluruhan menyangkut efektifitas, efisiensi, availability system, reliability, confidentiality, dan integrity, aspek security, audit atas proses, modifikasi program, audit atas sumber data, dan data file.

\section{Bantuan Operasional Sekolah (BOS)}

Bantuan Operasional Sekolah (BOS) adalah program pemerintah yang pada dasarnya penyediaan pendanaan biaya operasi nonpersonalia bagi satuan pendidikan dasar sebagai pelaksana program wajib belajar [5]. Pendanaan pendidikan adalah penyediaan sumber daya yang diperlukan untuk penyelenggaraan dan pengelolaan pendidikan. Sumber pendanaan pendidikan ditentukan berdasarkan prinsip keadilan, kecukupan, dan keberlanjutan [6].

\section{Pengertian Sistem}

Didalam mendefinisikan sebuah sistem, ada yang menggunakan suatu penekanan terhadap prosedur dan penekanan terhadap komponen atau elemennya. Sistem juga bisa dikatakan suatu jaringan kerja dari prosedur-prosedur yang saling berhubungan, berkumpul bersama-sama untuk melakukan suatu kegiatan atau untuk menyelesaikan suatu sasaran yang tertentu [7]. Dari pendapat yang dikemukakan diatas dapat disimpulkan bahwa sistem adalah suatu kumpulan atau kelompok dari elemen atau komponen yang saling berhubungan atau saling berinteraksi dan saling bergantung satu sama lain untuk mencapai tujuan tertentu yang dapat dilihat pada gambar 2 dibawah ini.

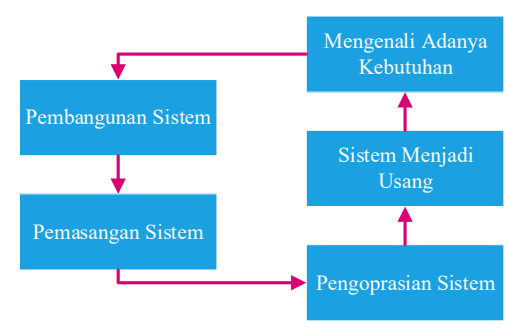

Gambar 2. Daur Hidup Sistem [8]

\section{E. Pengertian COBIT}

Control Objective for Information and Related Technology (COBIT) adalah salah satu kerangka bisnis untuk tata kelola dan manajemen perusahaan IT. Versi evolusiner ini menggabungkan pemikiran terbaru dalam tata kelola perusahaan dan teknik manajemen, serta menyediakan prinsipprinsip, praktek, alat-alat analisis dan model yang diterim secara global untuk membantu meningkatkan kepercayaan, dan nilai dari sistem informasi [9].

COBIT memiliki 5 proses model referensi COBIT (PRM) terdiri dari 37 proses menggambarkan siklus hidup untuk tata kelola TI, seperti yang ditunjukkan pada gambar 3 dibawah ini.

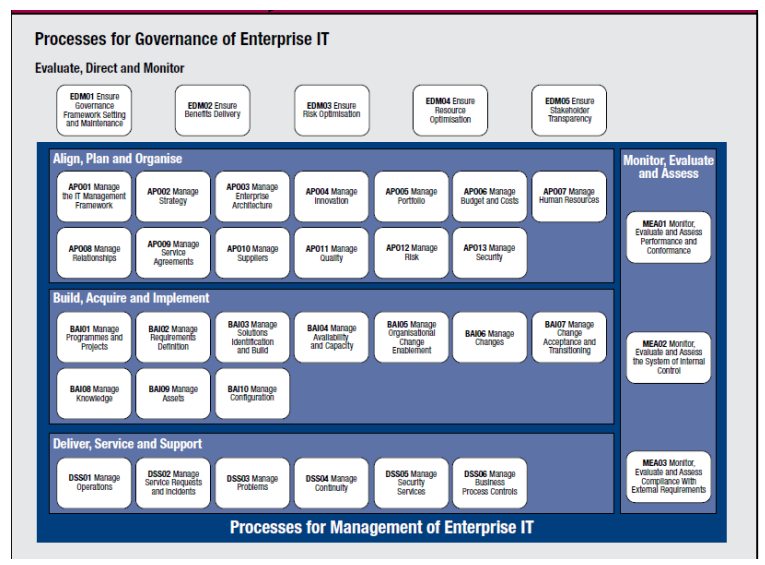

Gambar 3. Process Referece Model COBIT 5

\section{HASIL DAN PEMBAHASAN}

\section{A. Jenis Data dan Sumber Data}

1) Data Primer

Data mengacu pada informasi yang diperoleh dari tangan pertama oleh peneliti yang berkaitan dengan variabel minat untuk tujuan spesifik studi yang langsung memberikan data kepada pengumpul data [10]. Data primer dalam penelitian ini diperoleh dari kuesioner yang dilakukan penyebaran kepada user pengguna aplikasi SIBOS dari indikator tiap-tiap variabel yang digunakan di sekolah-sekolah yang berada di kabupaten bintan. Variabel-variabel tersebut diukur dengan menggunakan skala likert yang dapat dilihat pada tabel 1 dibawah ini. Skala likert digunakan untuk mengukur sikap, pendapat, dan persepsi seseorang atau sekelompok orang tentang fenomena sosial.

TABEL I

SKALA LIKERT [11]

\begin{tabular}{lc}
\hline \multicolumn{1}{c}{ Kategori } & Nilai \\
\hline Sangat Setuju (SS) & 5 \\
Setuju (S) & 4 \\
Ragu-ragu (RR) & 3 \\
Tidak Setuju (TS) & 2 \\
Sangat Tidak Setuju (STS) & 1 \\
\hline
\end{tabular}

2) Data Skunder

Sumber data yang tidak langsung memberikan data kepada pengumpul data. Dalam penelitian ini data 
sekunder merupakan data melalui pengujian dan informasi dari berbagai sumber yang sesuai dengan penelitian ini, yaitu:

a. Surat izin penelitian yang diperoleh dari Dinas Pendidikan Pemuda dan Olahraga Kabupaten Bintan.

b. Data mengenai sekolah-sekolah di Kabupaten Bintan.

c. Data terkait berbagai informasi sesuai dengan penelitian yang didapat melalui internet.

\section{B. Uji Validitas}

Suatu data dapat saja memiliki kualitas yang baik, tetapi belum tentu valid atau berguna jika tidak menunjang tercapainya tujuan si pemakai (user). Validitas adalah suatu skala pengukuran dikatakan valid apabila skala tersebut digunakan untuk mengukur apa yang seharusnya diukur. Untuk perhitungan uji validitas dapat dilihat pada persamaan (1) dibawah ini [12].

$$
r=\frac{n \sum X Y-\sum X \sum Y}{\sqrt{\left(\left(n \sum X^{2}-\left(\sum X\right)^{2}\right)\left(n \sum Y^{2}-\left(\sum Y\right)^{2}\right)\right)}}
$$

Keterangan :

$\begin{array}{lll}r & = & \text { Koefisien korelasi } \\ n & = & \text { Jumlah sampel data } \\ X & = & \text { Skor tiap item } \\ Y= & \text { Skor total item }\end{array}$

Uji validitas yang digunakan adalah dengan metode uji dua sisi (two-tailed test) dengan level of significance $(\dot{\alpha}=0.05)$.

1) Apabila $r$ hitung $\geqslant \mathrm{r}$ tabel maka item pertanyaan pada kuesioner yang di ajukan berkorelasi signifikan terhadap skor total (data valid).

2) Apabila $r$ hitung $\leqslant \mathrm{r}$ tabel maka item pertanyaan pada kuesioner yang di ajukan berkorelasi signifikan terhadap skor total (data tidak valid).

Hasil uji validasi dari penelitian ini dapat dilihat pada tabel 2 dibawah ini.

TABEL II

Hasil Uji VALIDITAS PENELITIAN

\begin{tabular}{cccc}
\hline No Soal & R-Hitung & R-Tabel & Hasil \\
\hline 1 & 0,3740 & 0,3610 & VALID \\
2 & 0,4070 & 0,3610 & VALID \\
3 & 0,4190 & 0,3610 & VALID \\
4 & 0,3920 & 0,3610 & VALID \\
5 & 0,7000 & 0,3610 & VALID \\
6 & 0,6210 & 0,3610 & VALID \\
7 & 0,7480 & 0,3610 & VALID \\
8 & 0,6470 & 0,3610 & VALID \\
9 & 0,7710 & 0,3610 & VALID \\
10 & 0,4760 & 0,3610 & VALID \\
11 & 0,5810 & 0,3610 & VALID \\
12 & 0,6500 & 0,3610 & VALID \\
13 & 0,5390 & 0,3610 & VALID \\
14 & 0,5440 & 0,3610 & VALID \\
15 & 0,6730 & 0,3610 & VALID \\
16 & 0,5240 & 0,3610 & VALID \\
17 & 0,5570 & 0,3610 & VALID \\
18 & 0,5710 & 0,3610 & VALID \\
19 & 0,4140 & 0,3610 & VALID \\
20 & 0,6200 & 0,3610 & VALID \\
21 & 0,6130 & 0,3610 & VALID \\
22 & 0,5720 & 0,3610 & VALID \\
\hline
\end{tabular}

TABEL II

(LANJUTAN)

\begin{tabular}{cccc}
\hline No Soal & R-Hitung & R-Tabel & Hasil \\
\hline 23 & 0,5840 & 0,3610 & VALID \\
24 & 0,5360 & 0,3610 & VALID \\
\hline
\end{tabular}

Pada tabel 2 diatas merupakan hasil uji validitas, untuk menguji validitas konstruk dilakukan dengan cara mengkorelasikan antara skor butir pertanyaan dengan skor total. Dalam penelitian ini jumlah responden atau $\mathrm{N}$ ialah 40 , maka df nya ialah 38 , karena $\mathrm{df}=\mathrm{N}-2$, maka $40-2=38$. Nilai $\mathrm{R}$ dari df $=38$ ialah 0.3610 .

\section{Proses Domain DSS (Deliver, Service, and Support) pada COBIT 5.0}

Secara garis besar domain DSS (Deliver, Service, Support) terbagi menjadi 6 (enam) proses utama yakni: DSS01 \pm Manage operation: Mengelola operasi; DSS02 \pm Manage service request and incidents : Mengelola layanan permintaan dan kasus; DSS03 \pm Manage problems : Mengelola permasalahan ; DSS04 \pm Manage continuity: Mengelola kelancaran; DSS05 \pm Manage security Service: Mengelola layanan keamanan; DSS06 \pm Manage business process controls : mengelola kontrol proses bisnis.

Penyusunan kuisioner haruslah sesuai dengan metode yang diterapkan dalam penelitian, dalam hal ini ialah metode COBIT domin DSS (Deliver, Service, and Support). Hal ini dilakukan agar kuisioner yang disusun tidak melenceng dari aktivitas atau proses yang ada serta sesuai dengan metode COBIT 5. 0 domain DSS (Deliver, Service, and Support), maka akan dilakukan pemetaan dari proses yang telah dipilih.

TABEL III

COBIT PADA DOMAIN DSS (DELIVER, SERVICE, AND SUPPORT) [13]

\begin{tabular}{|c|c|c|c|}
\hline No & Domain & Proses & Area \\
\hline 1 & $\begin{array}{c}\text { Deliver, Service } \\
\text { and Support } \\
\text { (DSS) }\end{array}$ & $\begin{array}{l}\text { DSS01 Mengelola Operasi } \\
\text { DSS02 Mengelola } \\
\text { Permintaan Layanan dan } \\
\text { Mengelola Insiden } \\
\text { DSS03 Mengelola Masalah } \\
\text { DSS04 Mengelola } \\
\text { Keberlanjutan } \\
\text { DSS05 Mengelola Layanan } \\
\text { Keamanan } \\
\text { DSS06 Mengelola Kontrol } \\
\text { Proses Bisnis }\end{array}$ & Management \\
\hline
\end{tabular}

\section{Rekap Pengujian Data Kuesioner}

Kuesioner pada penelitian yang penulis lakukan adalah menggunakan kuesioner. Kuesioner telah diisi oleh 40 responden yang dimulai dari bulan Oktober 2019 s.d November 2019 . Responden merupakan user SIBOS yaitu operator, tata usaha, bendahara, dan guru.

Setelah kuesioner diisi oleh responden, maka penulis merekap hasil kuesioner yang telah diisi oleh responden. Tabel dibawah ini adalah kuesioner yang telah diisi oleh 40 responden, dapat dilihat pada tabel 4 dibawah ini. 
TABEL IV

HASIL KUESIONER YANG TELAH DI INPUT

\begin{tabular}{|c|c|c|c|c|c|c|}
\hline \multirow{2}{*}{ Domain } & \multirow{2}{*}{ Soal No } & \multicolumn{5}{|c|}{ Bobot } \\
\hline & & 5 & 4 & 3 & 2 & 1 \\
\hline \multirow{10}{*}{ DSS 01} & 1 & 10 & 13 & 6 & 5 & 6 \\
\hline & 2 & 10 & 15 & 6 & 5 & 4 \\
\hline & 3 & 11 & 13 & 7 & 4 & 5 \\
\hline & 4 & 15 & 9 & 5 & 9 & 2 \\
\hline & 5 & 10 & 12 & 9 & 4 & 5 \\
\hline & 6 & 11 & 11 & 11 & 3 & 4 \\
\hline & 7 & 18 & 9 & 6 & 0 & 7 \\
\hline & 8 & 20 & 7 & 4 & 4 & 5 \\
\hline & 9 & 13 & 10 & 7 & 4 & 6 \\
\hline & 10 & 14 & 10 & 6 & 2 & 8 \\
\hline \multirow{3}{*}{ DSS 02} & 11 & 11 & 8 & 11 & 6 & 4 \\
\hline & 12 & 16 & 11 & 3 & 5 & 5 \\
\hline & 13 & 6 & 19 & 7 & 3 & 5 \\
\hline \multirow[t]{3}{*}{ DSS 03} & 14 & 11 & 10 & 6 & 6 & 7 \\
\hline & 15 & 7 & 13 & 10 & 5 & 5 \\
\hline & 16 & 15 & 11 & 5 & 2 & 7 \\
\hline \multirow{2}{*}{ DSS 04} & 17 & 10 & 12 & 6 & 6 & 6 \\
\hline & 18 & 15 & 10 & 4 & 6 & 5 \\
\hline \multirow{2}{*}{ DSS 05} & 19 & 21 & 6 & 3 & 2 & 8 \\
\hline & 20 & 17 & 9 & 6 & 2 & 6 \\
\hline \multirow{4}{*}{ DSS 06} & 21 & 15 & 11 & 6 & 5 & 3 \\
\hline & 22 & 12 & 11 & 10 & 5 & 2 \\
\hline & 23 & 21 & 5 & 6 & 2 & 6 \\
\hline & 24 & 13 & 10 & 8 & 3 & 6 \\
\hline \multicolumn{2}{|c|}{ Skor } & 322 & 255 & 158 & 98 & 127 \\
\hline \multicolumn{2}{|c|}{ Bobot x Skor } & 1610 & 1020 & 474 & 196 & 127 \\
\hline
\end{tabular}

\section{E. Analisis Data}

1) Domain Mengelola Operasi (Managed Operation) Pada domain ini, terdapat 4 sub domain. Dari data responden, dapat diketahui jumlah yang menjawab untuk setiap pertanyaan untuk domain DSS 01 (Mengelola Operasi) yang tampak pada tabel 5 di bawah ini.

TABEL V

JUMLAH JAWABAN RESPONDEN UNTUK DOMAIN DSS 01

\begin{tabular}{lccccc}
\hline \multirow{2}{*}{ Jumlah Soal (10) } & \multicolumn{5}{c}{ Bobot } \\
\cline { 2 - 6 } & $\mathbf{5 ( S S )}$ & $\mathbf{4}(\mathbf{S})$ & $\mathbf{3}(\mathbf{R})$ & $\mathbf{2}(\mathbf{K S})$ & $\mathbf{1}(\mathbf{T S})$ \\
\hline DSS 01.01 & 31 & 41 & 19 & 14 & 15 \\
DSS 01.03 & 15 & 9 & 5 & 9 & 2 \\
DSS 01.04 & 39 & 32 & 26 & 7 & 16 \\
DSS 01.05 & 47 & 27 & 17 & 10 & 19 \\
Total & 132 & 109 & 67 & 40 & 52 \\
Score & 660 & 436 & 201 & 80 & 52 \\
\hline Indeks & \multicolumn{5}{c}{3,57} \\
Tingkat kapabilitas & \multicolumn{5}{c}{$71,5 \%$} \\
Rating Scale & \multicolumn{5}{c}{} \\
\hline
\end{tabular}

2) Domain Mengelola Permintaan Layanan dan Insiden (Managed Service Request and Incidents)

Pada domain ini, terdapat $2 \mathrm{sub}$ domain. Dari data responden, dapat diketahui jumlah yang menjawab untuk setiap pertanyaan untuk domain DSS 02 (Managed Service Request and Incidents) yang tampak pada tabel 6 di bawah ini.
TABEL VI

JUMLAH JAWABAN RESPONDEN UNTUK DOMAIN DSS 02

\begin{tabular}{lccccc}
\hline \multirow{2}{*}{ Jumlah Soal (2) } & \multicolumn{5}{c}{ Bobot } \\
\cline { 2 - 6 } & $\mathbf{5 ( S S )}$ & $\mathbf{4}(\mathbf{S})$ & $\mathbf{3}(\mathbf{R})$ & $\mathbf{2}(\mathbf{K S})$ & $\mathbf{1}(\mathbf{T S})$ \\
\hline DSS 02.02 & 11 & 8 & 11 & 6 & 4 \\
DSS 02.05 & 16 & 11 & 3 & 5 & 5 \\
Total & 27 & 19 & 14 & 11 & 9 \\
Score & 135 & 76 & 42 & 22 & 9 \\
\hline Indeks & \multicolumn{5}{c}{3,55} \\
Tingkat kapabilitas & \multicolumn{5}{c}{$71,0 \%$} \\
Rating Scale & \multicolumn{5}{c}{} \\
\hline
\end{tabular}

3) Domain Mengelola Masalah (Managed Problem) Pada domain ini, terdapat 3 sub domain. Dari data responden, dapat diketahui jumlah yang menjawab untuk setiap pertanyaan untuk domain DSS 03 (Managed Problem) yang tampak pada tabel 7 di bawah ini.

TABEL VII

JUMLAH JAWABAN RESPONDEN UNTUK DOMAIN DSS 03

\begin{tabular}{lccccc}
\hline \multirow{2}{*}{ Jumlah Soal (3) } & \multicolumn{5}{c}{ Bobot } \\
\cline { 2 - 6 } & $\mathbf{5 ( S S )}$ & $\mathbf{4}(\mathbf{S})$ & $\mathbf{3}(\mathbf{R})$ & $\mathbf{2}(\mathbf{K S})$ & $\mathbf{1}(\mathbf{T S})$ \\
\hline DSS 03.01 & 6 & 19 & 7 & 3 & 5 \\
DSS 03.03 & 11 & 10 & 6 & 6 & 7 \\
DSS 03.05 & 7 & 13 & 10 & 5 & 5 \\
Total & 24 & 42 & 23 & 14 & 17 \\
Score & 120 & 168 & 69 & 28 & 17 \\
\hline Indeks & \multicolumn{5}{c}{3,35} \\
Tingkat kapabilitas & \multicolumn{5}{c}{$67,0 \%$} \\
Rating Scale & \multicolumn{5}{c}{} \\
\hline
\end{tabular}

4) Domain Mengelola Keberlanjutan (Managed Contiunity)

Pada domain ini, terdapat $3 \mathrm{sub}$ domain. Dari data responden, dapat diketahui jumlah yang menjawab untuk setiap pertanyaan untuk domain DSS 04 (Managed Contiunity) yang tampak pada tabel 8 di bawah ini.

TABEL VIII

JUMLAH JAWABAN RESPONDEN UNTUK DOMAIN DSS 04

\begin{tabular}{lccccc}
\hline \multirow{2}{*}{ Jumlah Soal (3) } & \multicolumn{5}{c}{ Bobot } \\
\cline { 2 - 6 } & $\mathbf{5 ( S S )}$ & $\mathbf{4}(\mathbf{S})$ & $\mathbf{3}(\mathbf{R})$ & $\mathbf{2}(\mathbf{K S})$ & $\mathbf{1}(\mathbf{T S})$ \\
\hline DSS 04.03 & 25 & 23 & 11 & 8 & 13 \\
DSS 04.07 & 15 & 10 & 4 & 6 & 5 \\
Total & 40 & 33 & 15 & 14 & 18 \\
Score & 200 & 132 & 45 & 28 & 18 \\
\hline Indeks & \multicolumn{5}{c}{3,53} \\
Tingkat kapabilitas & \multicolumn{5}{c}{$40,5 \%$} \\
Rating Scale & \multicolumn{5}{c}{} \\
\hline
\end{tabular}

5) Domain Mengelola Layanan Keamanan (Managed Security Service)

Pada domain ini, terdapat 1 sub domain. Dari data responden, dapat diketahui jumlah yang menjawab untuk setiap pertanyaan untuk domain DSS 05 (Managed Security Service) yang tampak pada tabel 9 di bawah ini. 
TABEL IX

JUMLAH JAWABAN RESPONDEN UNTUK DOMAIN DSS 05

\begin{tabular}{lccccc}
\hline \multirow{2}{*}{ Jumlah Soal (2) } & \multicolumn{5}{c}{ Bobot } \\
\cline { 2 - 6 } & $\mathbf{5 ( S S )}$ & $\mathbf{4}(\mathbf{S})$ & $\mathbf{3}(\mathbf{R})$ & $\mathbf{2}(\mathbf{K S})$ & $\mathbf{1}(\mathbf{T S})$ \\
\hline DSS 05.04 & 38 & 15 & 9 & 4 & 14 \\
Total & 38 & 15 & 9 & 4 & 14 \\
Score & 190 & 60 & 27 & 8 & 14 \\
\hline Indeks & \multicolumn{5}{c}{3,74} \\
Tingkat kapabilitas & \multicolumn{5}{c}{$44,8 \%$} \\
Rating Scale & \multicolumn{5}{c}{} \\
\hline
\end{tabular}

6) Domain Mengelola Kontrol Proses Bisnis (Managed Business Process Control)

Pada domain ini, terdapat 3 sub domain. Dari data responden, dapat diketahui jumlah yang menjawab untuk setiap pertanyaan untuk domain DSS 06 (Managed Business Process Control) yang tampak pada tabel 10 di bawah ini. TABEL X

JUMLAH JAWABAN RESPONDEN UNTUK DOMAIN DSS 05

\begin{tabular}{lccccc}
\hline \multirow{2}{*}{ Jumlah Soal (4) } & \multicolumn{5}{c}{ Bobot } \\
\cline { 2 - 6 } & $\mathbf{5 ( S S )}$ & $\mathbf{4}(\mathbf{S})$ & $\mathbf{3}(\mathbf{R})$ & $\mathbf{2}(\mathbf{K S})$ & $\mathbf{1}(\mathbf{T S})$ \\
\hline DSS 06.01 & 15 & 11 & 6 & 5 & 3 \\
DSS 06.02 & 12 & 11 & 10 & 5 & 2 \\
DSS 06.03 & 34 & 15 & 14 & 5 & 12 \\
Total & 61 & 37 & 30 & 15 & 17 \\
Score & 305 & 148 & 90 & 30 & 17 \\
\hline Indeks & \multicolumn{5}{c}{3,69} \\
Tingkat kapabilitas & \multicolumn{5}{c}{$43,8 \%$} \\
Rating Scale & \multicolumn{5}{c}{} \\
\hline
\end{tabular}

\section{F. Hasil Penelitian}

1) Hasil Perhitungan Tingkat Kematangan (Capability Level) SIBOS kabupaten Bintan

TABEL XI

TABEL CAPABILITY LEVEL PER SUB DOMAIN

\begin{tabular}{cclc}
\hline NO & DOMAIN & \multicolumn{1}{c}{ PROSES } & Capability Level \\
\hline 1 & DSS 01 & Mengelola Operasi & 4 \\
2 & DSS 02 & $\begin{array}{l}\text { Mengelola Permintaan Layanan } \\
\text { dan Mengelola Insiden }\end{array}$ & 4 \\
3 & DSS 03 & Mengelola Masalah & 3 \\
4 & DSS 04 & Mengelola Keberlanjutan & 4 \\
5 & DSS 05 & Mengelola Layanan Keamanan & 4 \\
6 & DSS 06 & $\begin{array}{l}\text { Mengelola Kontrol Proses } \\
\text { Bisnis }\end{array}$ & 4 \\
\hline
\end{tabular}

Berdasarkan analisis data yang dilakukan, maka dapat ditentukan tingkat capability level dari domain DSS dapat dilihat pada gambar 3 berikut.

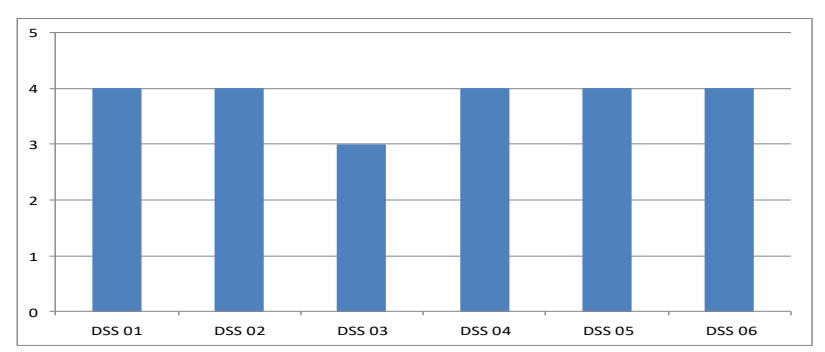

Gambar 3. Grafik Capability Level per sub Domain
2) Hasil Perhitungan Skala Rating (Rating Scale) SIBOS Setelah menghitung rata-rata dari Capability Level, selanjutnya adalah menghitung rata-rata rating scale SIBOS akan dihitung dari data yang ada pada tabel 11 dan gambar 4 dibawah ini.

TABEL XII

TABEL RATING SCALE PER SUB DOMAIN

\begin{tabular}{cclc}
\hline NO & DOMAIN & \multicolumn{1}{c}{ PROSES } & Rating Scale \\
\hline 1 & DSS 01 & Mengelola Operasi & $71,5 \%$ \\
2 & DSS 02 & $\begin{array}{l}\text { Mengelola Permintaan Layanan } \\
\text { dan Mengelola Insiden }\end{array}$ & $71,0 \%$ \\
3 & DSS 03 & Mengelola Masalah & $67,0 \%$ \\
4 & DSS 04 & Mengelola Keberlanjutan & $70,5 \%$ \\
5 & DSS 05 & Mengelola Layanan Keamanan & $74,8 \%$ \\
6 & DSS 06 & $\begin{array}{l}\text { Mengelola Kontrol Proses } \\
\text { Bisnis }\end{array}$ & $73,8 \%$ \\
\hline
\end{tabular}

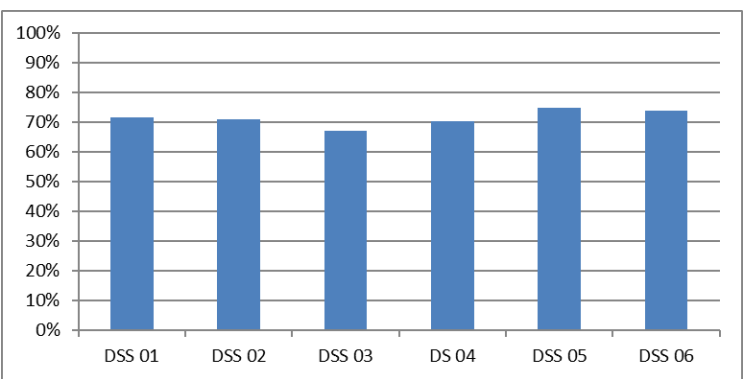

Gambar 4. Grafik Rating Scale per sub domain

\section{G. Efektifitas SIBOS}

Setelah data kuesioner diproses dan telah didapatkan tingkat kapabilitas beserta skala penilaian setiap domain dan dilengkapi dengan rata-ratanya, dapat dilihat bahwa SIBOS sudah memiliki tingkat efektifitas yang cukup tinggi berada pada nilai 3,83 atau level 4 (Predictablel Process). SIBOS telah memiliki fitur atau layanan sesuai dengan kebutuhan pada saat SIBOS digunakan, dimana aplikasi SIBOS telah menyediakan fitur sesuai dengan yang dibutuhkan oleh sekolah, dan SIBOS telah menjalankan proses TI dalam batasan-batasan yang sudah pasti, misal batasan waktu yang dihasilkan dari pengukuran yang telah dilakukan pada saat pelaksanaan proses TI tersebut sebelumnya jadi hanya perlu di tingkatkan. Hanya saja masih memiliki beberapa kekurangan dan kekurangan itu telah di tangani dengan melakukan inovasiinovasi yang berkelanjutan Selain itu, skala penilaian berdasarkan penelitian ini adalah largely achieved yaitu pada angka $71,43 \%$. Yang berarti sistem informasi sudah sesuai dengan yang di harapkan,dalam kondisi bagus dan relevan, sebagian besar dicapai, tidak ada kelemahan signifikan terkait dengan atribut ini yang mungkin ada dalam proses penilaian

\section{H. Rekomendasi}

1) Sering terjadi terjadi conection internet yang buruk, ini bisa di antisipasi dengan cara menambah speed dari internert itu sendiri salah satunya ialah mengubah menjadi processor clock speed yang artinya mempercepat dan memperlancar jaringan internet, sehingga dapat mengatasi jaringan internet yang buruk. 
2) Semakin banyak yang Login pada aplikasi SIBOS membuat kinerja semakin terhambat, sehingga sering terjadi (not responding) akibat banyaknya yang login di server tersebut. Hal ini dapat di atasi dengan menggunakan Content Delivery Network (CDN) Banyak keuntungan yang bisa anda dapatkan dengan menggunakan Content Delivery Network (CDN). CDN dapat membantu mempercepat akses ke aplikasi dengan cara menyimpan aset dalam kumpulan server. CDN juga membantu agar server selalu stabil walaupun banyak yang login.

\section{KESIMPULAN}

Berdasarkan kesimpulan dari hasil penelitian dapat disimpulkan bahwa layanan SIBOS memiliki pengaruh langsung dan secara signifikan terhadap kegiatan pengelolaan dana BOS. Maka peneliti menyarankan sebagai berikut :

1) Untuk Dinas Pendidikan kabupaten Bintan sebaiknya terus meningkatkan kualitas layanan dengan kolektibilitas yang semakin membaik, agar penerapan SIBOS dapat maksimal sehingga proses pengelolahan dapat berjalan lancar dan terus berkembang.

2) Sering terjadi terjadi conection internet yang buruk, ini bisa di antisipasi dengan cara menambah speed dari internert itu sendiri salah satunya ialah mengubah menjadi Processor clock speed yang artinya mempercepat dan memperlancar jaringan internet, sehingga dapat mengatasi jaringan internet yang buruk.

3) Semakin banyak yang Login pada aplikasi SIBOS membuat kinerja semakin terhambat, sehingga sering terjadi (Not Responding) akibat banyaknya yang login di server tersebut. Hal ini dapat di atasi dengan menggunakan Content Delivery Network (CDN) Banyak keuntungan yang bisa anda dapatkan dengan menggunakan Content Delivery Network (CDN). CDN dapat membantu mempercepat akses ke aplikasi dengan cara menyimpan aset dalam kumpulan server. CDN juga membantu agar server selalu stabil walaupun banyak yang login.

4) Aplikasi baru ini. Diharapkan peneliti selanjutnya dapat meneliti lebih lanjut dengan masalah yang lebih mendalam. Pendalaman dalam penelitian ini diharapkan dari jumlah sampel yang diperluas, serta variabel-variabel bebas lain yang tidak diteliti oleh peneliti sebelumnya.

\section{REFERENSI}

[1] Wibowo, A Satriani., Selo., Dani Adipta., Kombinasi Framework COBIT 5, ITIL Dan ISO/IEC 27002 Untuk Membangun Model Tata Kelola Teknologi Informasi Di Perguruan Tinggi, Yogyakarta: Seminar Nasional Teknologi Informasi Dan Komunikasi, Maret. 2016.

[2] Damayanti, Selvia., Negara, E Surya., Diana, Evaluasi Tata Kelola TI pada Sekretariat DPRD Provinsi Sumatra Selatan Menggunakan COBIT 5, Palembang : Jurnal Bima Komputer, Vol. 1, No. 2, Juli. 2019.

[3] Chandra, R Kurnia., Atastina, Imelda., Firdaus, Yuandar., Audit Teknologi Informasi menggunakan Framework COBIT 5 pada Domain DSS (Delivery, Service, and Support) (Studi Kasus : iGracias Telkom University), Bandung : e-Proceeding of Engineering, Vol. 2, No. 1, April. 2015.

[4] Angelia, Michelle., ddk, Audit Sitem Informasi Absensi pada PT Sinar Pratama Agung Menggunakan Kerangka KerjaCOBIT 4.1, Jakarta : Jurnal Ilmiah Rekayasa dan Manajemen Sistem Informasi, Vol 4, No.2, Agustus. 2018.
[5] Kemendiknas, Petunjuk Teknis Penggunaan Pertanggung Jawaban Keuangan Dana Bantuan Operasional Sekolah Tahun 2014, Jakarta : Dekdikbud, 2013.

[6] ilele, E., \& Sabijono, H., Evaluasi Pengelolaan Dana Bantuan Operasional Sekolah (BOS) (Studi Kasus Pada SD Inpres 4 Desa Akediri Kecamatan Jailolo Kabupaten Halmahera Barat), Tangerang : Jurnal Riset Ekonomi, Manajemen, Bisnis Dan Akuntansi, Vol. 17, Issue. 1, Januari. 2017

[7] Jogiyanto, HM, MBA, Akt, Analisis dan Desain,Yogyakarta : Andi, 2015 .

[8] Fauzan, Rauf., Latifah, Rani., Audit Tata Kelola Teknologi Informasi Untuk Mengontrol Manajemen Kualitas Menggunakan Cobit 4.1 (Studi Kasus : PT Nikkatsu Electric Works), Bandung : Jurnal Teknik Informatika dan Sistem Informasi, Vol. 1, No. 3, Desember. 2015.

[9] Isaca, COBIT Process Assessment Model (PAM): Using COBIT 5, United State of America : Rolling Meadows, 2013.

[10] Sugiyono, Metode Penelitian Kombinasi (Mix Methods), Bandung : Alfabeta, 2015.

[11] Vivi, Herlina, Panduan Praktis Mengolah Data kuesioner Menggunakan SPSS, Jakarta : PT Alex Media Komputindo, 2019.

[12] Rahmi, E Putri., Penilain Kapablitas Proses Tata Kelola TI Berdasarkan Proses DS001 pada Frame Work COBIT 5.0, Padang : Jurnal CoreIT, Vol. 2, No. 1, Juni. 2016.

[13] Isaca, COBIT 5 A Business Framework for the Governance and Management of Enterprise IT, 2012 